\title{
DIFERENTES PERSPECTIVAS SOBRE UMA EDUCAÇÃO ESTÉTICA NA ATUALIDADE
}

\author{
DIFERENTES PERSPECTIVAS SOBRE LA EDUCACIÓN EN LA ACTUALIDAD
}

DIFFERENT PERSPECTIVES ON AESTHETIC EDUCATION NOWADAYS

\author{
Luiz Antonio Calmon Nabuco LASTÓRIA ${ }^{1}$
}

RESUMO: A remissão à sensibilidade humana, à dimensão do "sensível" como objeto da educação propriamente dito encontra a sua formulação mais longínqua na República, de Platão, no entanto essa tarefa permaneceu um problema carente de uma equação razoável até os dias atuais. No Brasil, sobretudo após a publicação dos Parâmetros Curriculares Nacionais a partir de 1997, as discussões e proposições para a efetivação de uma educação do sensível se intensificaram. Nosso propósito, nos limites deste artigo, consiste na exposição e na problematização de duas diferentes perspectivas teóricas situadas em diferentes paisagens históricas do século XX, e que embasam as discussões no âmbito nacional a propósito de uma pretensa educação sensível na atualidade. Esse é o caso do psicólogo e teórico soviético Lev S. Vygotsky (1896) e do filósofo francês Jacques Rancière (1940).

PALAVRAS-CHAVE: Educação estética. Civilização. Contemporâneo.

RESUMEN: La referencia a la sensibilidad humana, a la dimensión de lo "sensible" como el objeto de la educación misma, encuentra su formulación más distante en la República de Platón, sin embargo, esta tarea ha seguido siendo un problema que carece de una ecuación razonable hasta nuestros días. En Brasil, especialmente después de la publicación de los Parámetros Curriculares Nacionales desde 1997, las discusiones y propuestas para la realización de una educación de la sensibilidad se intensificaron. Nuestro propósito, considerando los límites de esta investigación, consiste en la exposición y problematización de dos perspectivas teóricas diferentes situadas en diferentes paisajes históricos del siglo XX, y que subyacen a las discusiones a nivel nacional sobre una educación supuestamente sensible en la actualidad. Es el caso del psicólogo y teórico soviético Lev S. Vygotsky (1896) y del filósofo francés Jacques Rancière (1940).

PALABRAS CLAVE: Educación estética. Civilizacion. Contemporáneo.

ABSTRACT: The reference to human sensibility, to the dimension of the "sensible" as the object of education itself, finds its most distant formulation in Plato's Republic. However, this task has remained a problem lacking a reasonable equation until now. In Brazil, especially after the publication of the National Curriculum Parameters in 1997, the discussions and propositions for an education of the sensibility have intensified. Our purpose, considering the

${ }^{1}$ Universidade Estadual Paulista (UNESP), Araraquara - SP - Brasil. Professor Doutor Livre-Docente vinculado ao Departamento de Psicologia da Educação. ORCID: https://orcid.org/0000-0002-9870-5687. E-mail: lacalmon@fclar.unesp.br

RPGE- Revista on line de Política e Gestão Educacional, Araraquara, v. 24, n. 2, p. 297-313, maio/ago., 2020. e-ISSN: 1519-9029. 
limits of this paper consists in the exposition and reflection of two different theoretical perspectives. They are situated in different historical moments of the twentieth century and they are important reference for the national debate regarding a supposedly education of sensibility nowadays. This is the case of Soviet psychologist and theorist Lev S. Vygotsky (1896) and of the French philosopher Jacques Rancière (1940).

KEYWORDS: Esthetics education. Civilization. Contemporary.

\section{Introdução}

A remissão à sensibilidade humana, à dimensão do "sensível" como objeto da educação propriamente dito encontra a sua formulação mais longínqua na República, de Platão, e a sua formulação moderna mais bem acabada nas ideias filosóficas do poeta e dramaturgo romântico Friedrich Schiller (1759-1805). Para Schiller a beleza encerraria um imperativo que deveria guiar as ações humanas tendo em vista a nossa natureza racional e sensível a um só tempo. $\mathrm{Na}$ experiência ordinária, e, portanto, empírica, a beleza se apresentaria apenas como uma tarefa a ser realizada; e, por ser inevitavelmente complementar ao dever moral (sollen), exigido de modo imperativo pela razão prática, tal como havia sido exposto por Immanuel Kant, uma educação estética (ou do sensível) se faria absolutamente necessária na visada schilleriana.

No entanto, essa tarefa permaneceu um problema carente de uma equação razoável até os dias atuais. Não apenas pelos paradoxos que envolvem o ato de educar, ato que extrapola quaisquer tipos de atividades programadas, muito em voga na atualidade, mas, sobretudo, porque a ordem dos afetos situa-se aquém da própria consciência humana. Motivo que levou Sigmund Freud (1981) a se referir à educação como uma das três profissões julgadas por ele como "impossíveis".

Em termos históricos, a experiência do nazismo certamente nos ofereceu eloquentes exemplos quanto ao fracasso de uma educação do sensível vinculada aos anseios supostamente civilizatórios sustentados por aquele regime. O exemplo de Friedrich Wilhelm Ruppert consta entre estes. Rosa S. Rose (2007) toma a figura de Ruppert - o bom pai de família que torturava e tocava violino - para se indagar acerca do vínculo entre cultura e iniquidade moral. "Como se pode tocar Schubert a noite, ler Rilke pela manhã e torturar ao meio dia?" Se pergunta a autora da obra El misterioso caso alemán: un intento de comprender Alemania a través de sus letras a propósito deste quase desconhecido personagem da história real do século XX. Se a pergunta nos incomoda, isto se deve ao fato de Ruppert dessacralizar a cultura que aprendemos a venerar, conclui a autora. 
La existencia histórica de Ruppert y sus representantes ha dado definitivamente al traste con uno de los más grandes y bellos ideales de la modernidad: que la cultura nos hace mejores; no solo cualitativamente, en cuanto seres humanos, sino también en nuestra dimensión ética. Todos los que valoramos la cultura somos deudores de este sueño del que nos ha arrancado un amargo despertar: Ruppert justificaría una nueva interpretación del celebérrimo dicho de Adorno segun el cual no puede haber poesía después de Auschwitz, y es que, si no puede haberla, no es porque la poesía seja demasiado noble para seguir existiendo tras la comprobación pública del horror, sino porque, despojada del deseo universal que la impulsaba, se habría vuelto inútil, un mero entretenimiento para almas sensibles en los ratos de ocio (ROSE, 2007, p. 17).

Longe de configurar como um caso isolado, Ruppert figura em meio a inúmeros outros casos dispersos no espaço e no tempo, e distintos em termos de (in)sensibilidade, por vezes aliada à crueldade. E, em que pese existirem diferenças históricas substantivas entre os fascismos europeus do século passado e as sociedades democráticas atuais, a proposição hodierna de uma "educação sensível" permanece entre os dilemas da civilização engendrados historicamente por meio do binômio cultura/barbárie. Dilemas que soçobram carentes de elaborações reflexivas suficientes para que práticas bárbaras não se repitam sob as novas formas, particularmente propiciadas pelas novas tecnológicas tornadas tão corriqueiras, e que se proliferam em meio à sociedade de mercado atual.

Sobre a imprescindibilidade acerca das elaborações conscientes alcançadas pela atividade reflexiva do pensamento nos parecem ainda instrutivas as seguintes palavras de Theodor W. Adorno:

A faculdade de julgar se mede pela firmeza do Eu. Mas, com isso, também por aquela dinâmica das pulsões que é confiada ao sentimento pela divisão psíquica do trabalho. [...] Contra a cisão do pensamento não adianta a síntese dos departamentos psíquicos tornados estranhos uns aos outros, nem a mistura terapêutica da ratio com fermentos irracionais, mas a autorreflexão sobre o elemento do desejo que, de maneira antitética, constitui o pensamento enquanto pensamento. É quando esse elemento se dissolve de um modo puro, sem resíduo heterônomo, na objetividade do pensamento, que ele se constitui num impulso em direção à utopia (ADORNO, 1992, p. 174).

No Brasil, sobretudo após a publicação dos Parâmetros Curriculares Nacionais a partir de $1997^{2}$, as discussões e proposições para a efetivação de uma educação do sensível se

${ }^{2}$ A esse respeito ver PCNs Livros 1 e 6. Em que pese algumas menções à dimensão estética constarem já no primeiro volume dos PCNs, caracterizando-a como uma das áreas de conhecimentos a serem operacionalizados em cada um dos ciclos de aprendizagem do ensino fundamental ministrado nos estabelecimentos de ensino dos Estados da Federação, e cuja pertinência deve se concretizar em termos de capacidade dos alunos de se servirem de "diferentes linguagens", dentre as quais as linguagens "plásticas"; isto a fim de "produzir, expressar e comunicar suas ideias, interpretar e usufruir das produções culturais, em contextos públicos e privados, atendendo à diferentes 
intensificaram. Em linhas gerais os autores partem de uma crítica à educação centrada exclusivamente na razão, e, por vezes, na especialização do conhecimento - o que pressupõe um processo de fragmentação e de abstração crescentes -; e, também, de uma crítica à vida cotidiana reprocessada sob os ditames de uma indústria da cultura ultra desenvolvida. As contribuições de autores como Michel Maffesoli (Elogio da razão sensível) e Jacques Rancière (A partilha do sensível) embasam, em grande medida, algumas das principais posições que tomam parte nessas discussões e proposições no âmbito da educação. Desse modo, a dimensão estética devidamente caracterizada pelo reposicionamento teórico de um suposto "sujeito integral", e carente de uma educação compatível com o seu ser, passou ao primeiro plano.

De outra parte, autores como Lev S. Vygotsky, G. Lukács e também aqueles vinculados a chamada Escola de Frankfurt têm sido mobilizados no sentido de trazer novas contribuições pertinentes à elucidação acerca da dimensão estética constitutiva dos processos educativos. Críticas ao mainstream da política educacional em vigência no Brasil, estas vertentes polemizam com aquelas posições que procuram revestir a proposição de uma possível educação estética servindo-se do slogan do "aprender a aprender"3.

Nosso propósito, nos limites deste artigo, consiste na exposição e na problematização de duas diferentes perspectivas teóricas situadas em diferentes paisagens históricas do século $\mathrm{XX}$, e que embasam as discussões no âmbito nacional a propósito de uma pretensa educação sensível na atualidade. Esse é o caso do psicólogo e teórico soviético Lev S. Vygotsky (1896), e do filósofo francês Jacques Rancière (1940).

O primeiro, imerso na ambiência histórica da então URSS, produziu sua fecunda obra em plena construção do socialismo desencadeado pela revolução de outubro de 1917, evidenciando a função da arte como técnica do sentimento e como forma específica de representação ideológica produzida socialmente. Motivo pelo qual a proposição de uma psicologia social da arte se justificaria para a construção de uma nova sociedade. O segundo, ex-aluno de Louis Althusser, participou da movimentação social em maio de 1968 na França, e, posteriormente, ao final dos anos 80, dedicou-se às relações entre educação, estética e política.

intenções e situações de comunicação", ela será tratada pormenorizadamente no sexto volume dos PCNs dedicado ao ensino das artes.

${ }^{3}$ Ilustrativos desta tendência são os trabalhos de N. Duarte. Arte e Educação contra o fetichismo generalizado na sociabilidade contemporânea. Perspectiva, Florianópolis, SC, v. 27, n. 2, 461-479, 2009. Disponível em: http://www.perspectiva.ufsc.br. Acesso em: set. 2019, e de L. H. Fabiano. Adorno, Arte e Educação: Negócio da arte como negação". Arte e Sociedade. Campinas, SP, v. 24, n. 83, p. 495-505, 2003. 
Vygotsky, em meio à construção do socialismo na URSS (1917), reconheceu os fenômenos estéticos na qualidade de uma "técnica social do sentimento"; razão pela qual a psicologia da arte nada mais seria do que uma "mediação" de natureza psicossocial, por excelência, entre o estado das forças produtivas e as diferentes representações ideológicas configuradas peculiarmente no âmbito da estética: “[...] nunca o estudo sociológico em si, sem o complemento do estudo psicológico, estará em condições de revelar a natureza imediata da ideologia" (VYGOTSKY, 2001, p. 12). Portanto, a mediação psicológica aplicada ao âmbito da estética seria imprescindível ao desvelamento das ideologias uma vez que, para o psicólogo soviético, [...] "a arte sistematiza um campo inteiramente específico do psiquismo do homem social - precisamente o campo do seu sentimento" (VYGOTSKY, 2001, p. 12).

Em sua Psicologia da arte, escrita entre os anos 1924 e 1926, Vygotsky dedicou um capítulo inteiramente à discussão com a psicanálise. Ele o fez no melhor espírito do marxismo vigente (apelo à objetividade histórica e ao espírito sistemático de síntese), e por entender que para uma apreensão adequada dos fenômenos estéticos, o aparato teórico-conceitual mobilizado por aquela corrente teórica, deveria transcender os limites demarcados pelas filosofias restritas à consciência humana. Em matéria de estética o autor compreende que seria preciso considerar que: "Nunca conseguiremos dizer com exatidão por que precisamente gostamos dessa ou daquela obra; quase não podemos externar em palavras aqueles mínimos aspectos essenciais importantes dessa emoção e, como já observava Platão no Íon (cf. 86) os próprios poetas são os que menos sabem por que meios criam" (VYGOTSKY, 2001, p. 81). Não obstante, vale sublinhar que Vygotsky rejeitará categoricamente a cisão concebida por Freud entre as dimensões da consciência e do inconsciente.

Uma vez que tanto na produção das obras como nas recepções das mesmas entram em jogo as forças inconscientes, reconhecíveis apenas mediante indícios percebidos conscientemente, toda "interpretação racional, que o artista ou leitor faz dessa ou daquela obra deve ser [...] considerada como racionalização [...] tardia, isto é, como alguma impressão ilusória, alguma justificação diante da própria razão, como explicação post factum inventado" (VYGOTSKY, 2001, p. 82). Ocorre que, na visão do autor soviético, a estética mesma voltada aos tradicionais estudos das artes, sempre se apoiou, de modo explícito ou não, em premissas psicológicas. À exceção da psicanálise, essas psicologias limitaram as suas explicações estéticas aos processos verificados em nível estritamente consciente. E, dessa sorte, passaram ao largo daquele ponto de tensão culminante - catarse - em que as emoções produzidas pelas 
criações artísticas estabelecem a divisa entre os fenômenos estéticos - as artes - e a vida quotidiana.

A esse respeito argumenta Vygotsky na esteira de Otto Rank e N. Sachs:

Tudo indica que o efeito dessas emoções é inteiramente diverso quando produzido pelas obras de arte, e essa mudança estética do efeito da emoção, que vai da fonte do angustiante à fonte do prazer, é o problema cuja solução só pode ser obtida através da análise da vida inconsciente do espírito (VYGOTSKY, 2001, p. 83, grifo nisso).

Vygotsky retornará, ainda que de passagem, às contribuições da psicanálise em sua Psicologia da arte (capítulo 9) para elaborar a sua compreensão acerca do conceito aristotélico de kátharsis. Importa-lhe estabelecer, de uma perspectiva materialista, a conexão teórica entre a dinâmica de emoções suscitadas quando da recepção do objeto estético, e a produção ativa de fantasias por parte do sujeito.

Como é sabido, o termo grego kátharsis, dizia respeito originalmente à purificação, à purgação, ou ainda, à consolação da alma pela satisfação de um dever no plano da moral. De acordo com N. Abbagnano (1982), este termo guarda a sua gênese, provavelmente, na medicina jônica exercida por Hipócrates. "Platão, em conformidade com sua ontologia do Bem, utilizouo num sentido moral e metafísico para designar a libertação paulatina dos prazeres"; algo como "uma espécie de treino preparatório para a separação total que advém com a morte" (ABBAGNANO apud LASTÓRIA, 2017, p. 170). No entanto, Aristóteles parece ter sido o primeiro a estender o significado do termo aos fenômenos de ordem estética em sua Poética. Para ele esse termo comportava um duplo sentido: médico e moral. Isto é: "uma espécie de tratamento das afecções (corpóreas ou espirituais) que não as anula; antes as reduz à medida compatível com as exigências próprias à razão" (LASTÓRIA, 2017, p. 170).

$\mathrm{Na}$ modernidade esse termo conservou, ao menos em parte, o seu significado original vinculado ao âmbito estético, e também ao âmbito psicologia, sobretudo da psicanálise. Vygotsky, por sua vez, incumbiu-se de reformular esse termo em sua acepção estritamente estética. A definiçãa de catarse, tal como atribuída por Aristóteles ao referir-se à tragédia em sua Poética, serviu-lhe de base: "É pois a tragédia imitação de um caráter elevado, completa e de certa extensão, em linguagem ornamentada e com as várias espécies de ornamentos distribuídas pelas diversas partes (do drama), (imitação que se efetua) não por narrativa, mas mediante atores e que, suscitando o 'terror e a piedade, tem por efeito a purificação das emoções" (ARISTÓTELES, 1993, p. 37). As emoções contrárias - terror e piedade -, mencionadas por Aristóteles como o ingrediente catártico, propriamente dito, suscitadas no 
expectador devido à conduta do herói trágico no curso do enredo, constituiria a equação do problema central da estética a ser clarificado por uma psicologia social da arte de índole materialista.

Para tanto, o autor soviético menciona, na esteira de Pliekhánov, uma opinião sustentada por Darwin acerca do princípio da antítese em nossos movimentos expressivos:

\begin{abstract}
Alguns estados d'alma suscitam certos movimentos habituais, que em sua primeira manifestação até agora fazem parte dos movimentos úteis; e vemos que em estado d'alma totalmente oposto existe uma tendência forte e involuntária a realizar movimentos de qualidade totalmente oposta, embora estes nunca possam trazer nenhum proveito (PLIEKHÁNOV apud VYGOTSKY, 2001, p. 268).
\end{abstract}

Mas se movimentos opostos realizados arbitrariamente pelo organismo mobilizam a ação de conjuntos de músculos também opostos, e, na medida em que a execução desses movimentos opostos sob o impacto de impulsos contrários integra-se ao repertório comportamental do homem, assim como também ocorre no caso dos organismos inferiores, Darwin argumentou no sentido de que se determinados atos se associam estritamente a certas sensações ou sentimentos seria absolutamente normal "supor que as ações de qualidade inteiramente oposta passem a ser realizadas de forma não arbitrária, como resultado da associação habitual sob o efeito de sensações ou sentimentos diametralmente opostos" (PLIEKHÁNOV apud VYGOTSKY, 2001, p. 268/9).

Então o efeito catártico produzido pela tragédia (Vygotsky o estende também à fábula e ao romance, bem como às demais objetivações artísticas), decorreria do princípio de antítese, tal como fora elucidado por Darwin, formalmente estetizado pelos artistas. Tudo se passaria como se a forma estética do gênero trágico nos levasse a praticar movimentos opostos simultâneos, cuja tensão emocional aumenta no decorrer da ação dramática, mas que não se deixa exaurir totalmente nas ações motoras voltadas ao exterior. Diferentemente, a tensão emotiva se vincula à fantasia possibilitada pela nossa faculdade imaginativa. A produção de emoções opostas constituiria, assim, o segredo da forma estética. Da fábula à tragédia, argumenta Vygotsky, “a lei da reação estética é uma só: encerra em si a emoção que se desenvolve em dois sentidos opostos e encontra sua destruição no ponto culminante, como uma espécie de curto-circuito. É esse processo que gostaríamos de definir com o termo catarse" (VYGOTSKY, 2001, p. 270/1).

Na visada vygotskyana, toda e qualquer obra de arte se constitui por uma antítese interna entre forma e conteúdo; e, a forma mesma contém o segredo da recepção estética na medida em que entra em contradição com o conteúdo das obras apagando-o ou destruindo-o por completo. 
Poderíamos dizer que a base da reação estética são as emoções suscitadas pela arte e por nós vivenciadas com toda realidade e força, mas encontram a sua descarga naquela atividade da fantasia que requer de nós a percepção da arte. Graças a esta descarga central, retém-se e recalca-se extraordinariamente o aspecto motor da emoção, e começa a nos parecer que experimentamos apenas sentimentos ilusórios. É nessa unidade entre sentimento e fantasia que se baseia qualquer arte. Sua peculiaridade imediata consiste em que, ao nos suscitar emoções voltadas para sentidos opostos, só pelo princípio de antítese retém a expressão motora das emoções e, ao pôr em choque impulsos contrários, destrói as emoções do conteúdo, as emoções da forma, acarretando a explosão e a descarga da energia nervosa (VYGOTSKY, 2001, p. 272).

Sabemos que desde a antiguidade aos fenômenos estético-catárticos era-lhe inerente um sentido fundamentalmente ético-político. Disso decorria a estreita relação entre a arte e a política, relação expressa, sobretudo, nas tragédias financiadas pela polis e vivenciadas pelo conjunto dos cidadãos na qualidade de rituais sócio-políticos. Rituais cuja finalidade era a de provocar a reflexão coletiva dos cidadãos sobre os dilemas da existência humana contextualizados na ambiência da organização política da cidade-estado. Pois bem, dissemos inicialmente que Vygotsky reconheceu os fenômenos estéticos como uma "técnica social do sentimento". Agora podemos acrescentar que, por meio dessa técnica, o homem, seja ele o produtor ou o receptor da arte, deve aprender a superar não apenas o sentimento de angústia, mas também os demais sentimentos engendrados em meio ao labor necessário à sua autoconservação.

Historicamente a arte esteve ligada ao trabalho, lembra-nos o autor soviético, motivo pelo qual os povos da antiguidade consideravam a arte como um complemento de qualquer trabalho pesado, dando vazão aos sentimentos angustiantes. Posteriormente, a arte se separou da atividade laboral, porém conservou o seu potencial de permitir a elaboração dos sentimentos mediante a catarse. Nesse sentido antevê-se o engodo inerente à concepção segundo a qual as emoções estéticas reduzem-se àquelas que cortam o seu vínculo com as atividades práticas.

Se a psicologia social da arte aponta para a catarse como a categoria central dos fenômenos propriamente estéticos é porque "a arte pode surgir onde existe simplesmente o sentimento vivo e intenso" (VYGOTSKY, 2001, p. 314). E, por intermédio desta técnica social, o homem pode vir a elaborar criativamente os seus sentimentos penosos de modo a superá-los, razão pela qual a percepção da arte também exige atividade criativa por parte daqueles que a percebem. Não basta procurar vivenciar sinceramente o sentimento que dominou o autor da obra, nem mesmo se ater à compreensão da estrutura da obra. Faz-se necessário superar criativamente os próprios sentimentos por meio da catarse. Mencionando Ovsiániko Kulikovski, o autor menciona que "o papel da música militar não consiste em suscitar emoções 
bélicas, mas antes em estabelecer um equilíbrio entre o organismo e o meio em um momento crítico para o organismo, e assim disciplinar, ordenar o seu funcionamento e permitir a descarga necessária a sua emoção, afastar o medo e como que abrir caminho para a bravura" (VYGOTSKY, 2001, p. 314).

Em oposição à teoria do contágio segundo a qual o sentimento brotado num indivíduo se espalha por meio da arte para a multidão, Vygotsky insiste na tese de que o sentimento é social por sua própria natureza. Pois:

A refundição das emoções fora de nós realiza-se por força de um sentimento social que foi objetivado, levado para fora de nós, materializado e fixado nos objetos externos da arte, que se tornaram instrumentos da sociedade. De maneira igual, a arte é uma técnica social do sentimento, um instrumento da sociedade através do qual incorpora ao ciclo da vida social, mas, ao contrário, torna-se pessoal, quando cada um nós vivencia uma obra de arte, converte-se em pessoal sem com isso deixar de ser social (VYGOTSKY, 2001, p. 315).

Assim caberia à sociedade dispor da arte na qualidade de técnica do sentimento para aprimorar-se no sentido ético e político; afinal, a arte deve estar para a vida assim como o vinho está para a uva.

Por fim, Vygotsky concordará parcialmente com Tolstói para quem a música deveria ser uma questão de Estado. Mas objetará com precisão sobre os limites da função pedagógica a ser exercida pela crítica oficial, e também sobre a utilização educacional da arte nas escolas com vistas à formação dos educandos. Claro está que para o autor soviético a arte representa "a mais importante concentração de todos os processos biológicos do indivíduo na sociedade", e "um meio de equilibrar o homem com o mundo nos momentos mais críticos e responsáveis da vida”(VYGOTSKY, 2001, p. 329). Razão pela qual não poderia ser ignorada no processo social de construção de um novo homem em meio à sociedade soviética em construção à época.

\section{II}

De outra perspectiva o filósofo francês J. Rancière considerou a dimensão estética como inseparável das configurações históricas e políticas próprias à experiência humana. Daí o leque de modos de sentir e de formas de exercício do poder, que, para o filósofo, se afigura como ingrediente indispensável ao diagnóstico das formas políticas de subjetivação do presente. Mas, diferentemente da perspectiva sustentada pela visada pós-moderna, não se trataria de reivindicar, desta vez, a vocação vanguardista da arte moderna de modo a vincular às novidades artísticas, os anseios de uma humanidade redimida ou emancipada pela via da sensibilidade. J. 
Rancière buscou refletir ao seu modo sobre os experimentos vanguardistas contemporâneos a partir das interfaces produzidas através de uma nova partilha do sensível, e por meio da qual as dimensões da estética e da vida cotidiana apresentam-se fusionados. Tais reflexões se situam contra o pano-de-fundo que abriga os discursos sobre o ocaso ou sobre a morte da arte, e pela crítica da espetacularização estético-política levada ao cabo pelo situacionismo francês (G. Debord); crítica que alcançou o apogeu político nos anos 60 do século passado. Rancière observa que o vanguardismo político no plano da estética se transformou em pensamento enlutado após a proclamação do fim das utopias.

Este pano-de-fundo define o contexto em que se inscrevem muitas das questões teóricas e das respostas trabalhadas pelo filósofo, mas não o seu objetivo maior. Qual seja: o de reestabelecer as condições de inteligibilidade acerca do debate em torno da estética compreendida como um "regime específico de identificação e pensamento das artes: um modo de articulação entre maneiras de fazer, formas de visibilidade dessas maneiras de fazer e modo de pensabilidade de suas relações, implicando uma determinada ideia da efetividade do pensamento" (RANCIÈRE, 2005, p. 13). Nesse sentido, prossegue o autor: "Definir as articulações desse regime estético das artes, os possíveis que elas determinam e seus modos de transformação, este é o objetivo da minha pesquisa [...]” (RANCIÈRE, 2005, p. 13).

Mas, o que devemos compreender, mais especificamente, por "partilha do sensível" implicando as relações estabelecidas entre a política e a estética? A princípio, um conjunto de evidências que revela um substrato comum, porém desigualmente compartilhado. A repartição das partes e dos lugares designados aos cidadãos "se funda numa partilha dos espaços, tempos e tipos de atividades" que circunscreve o modo como cada um participa do comum. Não obstante, outra partilha precede o fato de que os cidadãos, tal como asseverou Aristóteles em sua Política, tomam parte no fato de governar e de ser governado: aquela que determina os que tomam parte. Logo, a partilha do sensível nos permite visualizar quem pode tomar parte no comum em função daquilo que faz, do tempo requerido pela atividade e do espaço em que ocorre a sua atividade. Referindo-se a um exemplo fornecido por Platão acerca do lugar do artesão na polis, o autor extrai a seguinte conclusão: “Assim, ter esta ou aquela 'ocupação' define competências ou incompetências para o comum. Define o fato de ser ou não visível num espaço comum, dotado de uma palavra comum etc.” (RANCIÈRE, 2005, p. 16).

É, portanto, nestes termos que o autor compreende que na base de toda operação política reside uma estética compreendida nos termos de uma partilha prévia do sensível. Mas isso nada tem a ver com a estetização da política (ao menos nos termos de que falava Benjamin), nem com uma suposta perversão da política (captura da política pela arte de modo que o povo ou a 
nação sejam pensados como obra de arte - Wagner). Trata-se apenas de um conjunto de formas a-priori capaz de determinar o que se dá a sentir: "É um recorte dos tempos e dos espaços, do visível e do invisível, da palavra e do ruído que define ao mesmo tempo o lugar e o que está em jogo na política como forma de experiência” (RANCIÈRE, 2005, p. 16).

Ora, de nossa parte poderíamos conjecturar apressadamente que se a política consiste na arte de se mover entre as aparências, e se produz por meio dos sons (palavras), como insistiu H. Arendt, e também por meio de imagens (V. Flusser), então uma suposta educação do sensível deveria levar em consideração exatamente aquelas competências estabelecidas em termos de aprimorar nossas capacidades de ver, ouvir, julgar e de dizer; isto considerando tanto as propriedades do espaço, como as dos tempos possíveis no que concerne à experiência em relação ao comum. Pois, nos termos do autor: "a política ocupa-se do que se vê e do que se pode dizer sobre o que é visto, de quem tem a competência para ver e qualidade para dizer, das propriedades do espaço e dos possíveis do tempo" (RANCIÈRE, 2005, p. 17). Mas é preciso ter em conta que, para Rancière, tais objetivos educacionais já se assentam numa dimensão estética primeira a partir da qual poderíamos discutir as demais práticas nesse âmbito. Isto na medida em que as próprias práticas estéticas dizem respeito ao conjunto das atividades específicas no âmbito das artes que, por sua vez, "intervém na distribuição geral das maneiras de fazer e nas suas relações com as maneiras de ser e formas de visibilidade" (RANCIÈRE, 2005, p. 17).

A consideração platônica sobre o teatro e a escrita, destacada pelo autor, são modelares para pensarmos a estética no contemporâneo, sobretudo a partir do advento da internet. Na cena teatral própria à antiguidade clássica - espaço de atividade pública por excelência e "lugar de exibição dos fantasmas" -, a partilha das identidades, dos espaços e das atividades se encontrava embaralhada. O mesmo ocorre com a escrita que se tornou o veículo de circulação descontrolada da palavra por toda parte. A legitimidade da palavra e os possíveis efeitos dela decorrentes é que se veem corroídos. O veto platônico, tal como argumenta o autor, explicitaria uma posição conservadora consonante com uma determinada partilha do sensível concretizada por uma política antidemocrática por meio da qual a polis dança e canta a sua própria unidade comunitária estática.

Acompanhemos com mais vagar as considerações feitas por Rancière acerca desses dois grandes modelos de partilha propostos por Platão quanto à efetividade da palavra no ambiente da polis: o teatro e a escrita. Modelos que, conforme o autor, viriam a ser "formas de estruturação para o regime das artes em geral" (RANCIÈRE, 2005, p. 18). Platão opõe ao teatro e à escrita, e, portanto, à indeterminação das identidades e à deslegitimação da posição dos 
oradores, o que considera ser uma "boa forma de arte". Em relação à mudez dos signos materializados por meio da escrita e da pintura, e ao simulacro da movimentação dos corpos encenados publicamente (teatro), Platão identifica, conforme o autor:

[...] três formas de partilha do sensível estruturando a maneira pela qual as artes podem ser percebidas e pensadas como arte $e$ como formas de inscrição do sentido na comunidade. Essas formas definem como as obras ou performances 'fazem política', quaisquer que sejam as intenções que as regem, os tipos de inserção social dos artistas ou o modo como as formas artísticas refletem estruturas ou movimentos sociais (RANCIÈRE, 2005, p. 18-19).

Já nos termos de uma política que se pretende efetivamente democrática deve-se supor, de saída, a legitimidade de uma comunidade universal de leitores e de juízes competentes; isto é: pessoas capazes de compreensão e de discernimento próprio. Aqui, a pretensão kantiana quanto à construção de um possível mundo racional esclarecido se faz presente. No entanto devemos ter em conta que esse argumento capitulou na Europa letrada, sobretudo na Alemanha nazista, sob a forma de uma "comunidade desenhada tão somente pela circulação aleatória da letra" (RANCIÈRE, 2005, p. 19). Mas, como visto, Rancière se ocupa daquele regime primeiro de distribuição a partir do qual todas as demais práticas sociais têm lugar. Neste sentido, interessa-lhe como o teatro e a escrita, por exemplo, esses dois grandes modelos platônicos de efetividade sensível da palavra, mostram-se capazes de estruturar o regime das artes em geral conformando lógicas próprias em diferentes temporalidades.

O que mais importa à partilha do sensível, tal como propõe Rancière, é percebermos que as "artes nunca emprestam às manobras de dominação ou de emancipação mais do que lhes podem emprestar, ou seja, muito simplesmente, o que têm em comum com elas: posições e movimentos dos corpos, funções da palavra, repartições do visível e do invisível” (RANCIÈRE, 2005, p. 26). E ainda: “a autonomia de que podem gozar e a subversão que podem se atribuir repousam sobre a mesma base" (RANCIÈRE, 2005, p. 26).

É certo que para o autor toda política funda-se numa determinada partilha do sensível: teatro-coro de um lado e a página, de outro, tal como identificado por Platão. Na passagem do século XIX para XX, observa-se a extrapolação do modelo da página de modo a exceder a materialidade da folha escrita ensejando o que Rancière denomina por "democracia romanesca". Esta se caracterizaria por certa indiferença quanto à escrita, devidamente simbolizada pela forma do romance e do público que lhe corresponde. Obras como Madame Bovary e A educação sentimental foram imediatamente identificados como "democracia em literatura", argumenta o autor. Flaubert não teria confiado à literatura uma mensagem qualquer, 
não teria intencionado torná-la pedagógica. Ele apenas se propôs a "pintar" cenas com a mesma indiferença de tudo aquilo que pode advir sobre o papel perante quaisquer olhares, como a sua mais legítima opção poética. E é nesse sentido preciso que, para Rancière, o romance se põe em circulação como "democracia em literatura".

Também a cultura tipográfica e iconográfica que já havia demonstrado os seus poderes subversivos no Renascimento, ao tomar um novo impulso no período romântico serve de exemplo desse nó estético/político de que fala o autor. O entrelaçamento da letra com a imagem embaralhou "as regras de correspondência à distância entre dizível e o visível, próprias à lógica representativa" (RANCIÈRE, 2005, p. 20). Bem como embaralhou as noções de arte "pura" e "aplicada" ensejando o movimento Arts and Crafts, e os seus derivados (Art Déco, Bauhaus, construtivismo).

Já a superfície bidimensional trazida à tona pelo modernismo em oposição ao ponto de fuga perspectivista pretendia devolver à pintura o domínio do que lhe é próprio em relação à arquitetura. Aqui Rancière argumenta que uma superfície, seja ela qual for, não tem nada de "próprio" efetivamente; isto na medida em que se compõe como uma partilha do sensível. Se para Platão escrita e pintura sobre superfícies nada mais representavam do que "signos mudos", isto por estarem privadas daquele sopro - ânima - que as anima, a adoção renascentista da profundidade ótica, por sua vez, fora uma resposta estética que devolveu às pinturas o privilégio de estarem em conformidade com uma era que se compreendeu a si mesma como dotada de profundidade histórica. "Ela instaurou entre a palavra e a pintura, entre o dizível e o visível uma relação de correspondência à distância, dando à 'imitação' seu espaço específico" (RANCIÈRE, 2005, p. 22).

Ora, as análises empreendidas por Rancière nos revelam que na disputa entre a tridimensionalidade renascentista e a bidimensionalidade modernista questões de primeira ordem saltam do plano estético ao político. Senão vejamos:

É na superfície plana da página, na mudança de função das 'imagens' da literatura ou na mudança do discurso sobre o quadro, mas também nos entrelaces da tipografia, do cartaz e das artes decorativas, que se prepara uma boa parte da 'revolução antirrepresentativa' da pintura. Esta pintura [...] é parte de uma visão de conjunto de um novo homem, habitante de novos edifícios, cercado de objetos diferentes. Sua planaridade tem ligação com a da página, do cartaz ou da tapeçaria - é uma interface. E sua 'pureza' antirrepresentativa inscreve-se num contexto de entrelaçamento de arte pura e da arte aplicada, que lhe confere de saída uma significação política (RANCIÈRE, 2005, p. 22/23). 
Portanto, não seria a "febre revolucionária" que faria de um pintor como Malevitch um arauto das "novas formas de vida", e sim uma determinada partilha do sensível que criaria as interfaces entre diferentes suportes (poemas e ilustrações, teatro e grafistas, literatura e arte decorativa). A propósito dessa partilha conclui Rancière que:

Essa é política porque revoga a dupla política inerente à lógica representativa. Esta, por um lado, separava o mundo das imitações da arte do mundo dos interesses vitais e das grandezas político-sociais. Por outro, sua organização hierárquica - e particularmente o primado da palavra/ação viva sobre a imagem pintada - era análoga à ordem social. Com a vitória da página romanesca sobre a cena teatral, o entrelaçamento igualitário das imagens e dos signos na superfície pictural ou tipográfica, a promoção da arte dos artesãos à grande arte e a pretensão da nova de inserir arte no cenário de cada vida em particular, trata-se de todo um recorte ordenado da experiência sensível que cai por terra (RANCIÈRE, 2005, p. 23).

O filósofo compreende o que denomina por "regime de representação" da arte (situado entre o "regime ético" e o "regime estético") como uma estratégia destinada à estabilização da arte como uma espécie de "exceção extraordinária" no imaginário social. Do ponto de vista da atividade artística propriamente dita, esta passa a ser compreendida sobre a égide da técnica por meio da qual se produz a mimese (e não do simulacro adjetivado por Platão). Mas, de outra parte, mediante as operações próprias a esse mesmo regime de representação ofusca-se a visibilidade sensível da continuidade entre o tipo particular de atividade artística e as demais atividades sociais. Somente nesse regime se torna possível ao âmbito do pensamento estético inscrever as suas hierarquias, e também as suas exclusões, na divisão entre as chamadas artes liberais e as artes mecânicas.

Já no "regime estético" que o sucede, a nova partilha do sensível reconfigura não apenas os espaços, e tempos, mas o próprio estatuto do domínio da atividade artística. Nesse regime, argumenta o autor, dispõe-se da possibilidade material para perseguirmos o programa exposto por Schiller em suas Cartas sobre a educação estética do homem. Isso se torna possível porque a confecção de um objeto não mais é vista como imposição de uma forma do pensamento à matéria inerte (Aristóteles).

O programa romântico sustentado por Schiller pressupõe exatamente uma partilha do sensível em que os que agem decidindo, e os que sofrem as consequências dessas ações deveriam nos conduzir à superação desse estado de coisas suspendendo a oposição entre o entendimento ativo e a sensibilidade passiva. Quanto a essa suspensão referente ao valor negativo do trabalho, argumenta Rancière: 
[...] tornou-se, no século XIX, a afirmação de seu valor positivo como forma de efetividade comum do pensamento e da comunidade. Tal mutação passou pela transformação da suspensão, própria ao 'estado estético', em afirmação positiva da vontade estética. O romantismo proclama devir-sensível de todo pensamento e o devir pensamento de toda materialidade sensível como objetivo mesmo da atividade do pensamento em geral. A arte, assim, torna-se um símbolo do trabalho. Ela antecipa o fim - a supressão das oposições - que o trabalho ainda não está em condições de conquistar por e para si mesmo (RANCIÈRE, 2005, p. 66/67).

Porém o autor alerta para a possibilidade de uma compreensão errônea a esse respeito: a de que a atual valorização do trabalho decorra exclusivamente do novo pensamento estético. Este último segue sendo uma concepção do pensamento decorrente de uma nova partilha do sensível, quaisquer que sejam as especificidades dos circuitos econômicos nos quais se inserem.

\section{Conclusão}

Partimos da asserção de que uma educação estética, ou do sensível, permaneceu um problema carente de uma equação razoável até os dias atuais, e expusemos, sinteticamente, as contribuições de dois diferentes autores que se debruçaram sobre o lugar e a relevância da experiência estética em distintas paisagens históricas do século XX, perspectivas as quais têm sido retomadas suscitando inúmeras reflexões sobre o tema no âmbito da educação atual.

Vygotsky, em meio à construção do socialismo na URSS após 1917, reconheceu os fenômenos estéticos na qualidade de uma "técnica social do sentimento" da mais alta importância. Isto na medida em que, para ele, a arte representa: "a mais importante concentração de todos os processos biológicos do indivíduo na sociedade", e "um meio de equilibrar o homem com o mundo nos momentos mais críticos e responsáveis da vida" (VYGOTSKY, 2001, p. 329). Razão pela qual a arte não poderia ser ignorada no processo social de construção de um novo homem em meio à sociedade soviética em construção à época. A distinção entre a esfera artística e a vida cotidiana deveria ser mantida para que a função sociopsicológica da catarse estética pudesse se cumprir adequadamente. À educação caberia municiar os educandos daqueles conhecimentos específicos, acumulados e sistematizados ao longo da história, com o intuito de capacitá-los a esse tipo de experiência. Não obstante a fecundidade inerente às proposições teóricas do autor soviético, elas se distanciam historicamente das intrincadas questões suscitadas para uma educação do sensível em meio à indústria cultural contemporânea.

De outra perspectiva, o filósofo francês J. Rancière também considerou a dimensão estética como inseparável das configurações históricas e políticas próprias à experiência 
humana. No entanto esse autor identificou como o atual "regime estético" uma nova partilha do sensível que pressupõe a reconfiguração não apenas dos espaços, e tempos, mas do próprio estatuto do domínio da atividade artística. Nesse regime, conforme o seu argumento, dispomos da possibilidade material efetiva para perseguirmos o programa exposto por Schiller em suas Cartas sobre a educação estética do homem. Isso se torna possível porque a confecção de um objeto não mais é vista como imposição de uma forma do pensamento à matéria inerte (ARISTÓTELES, 1993).

O programa romântico sustentado por Schiller pressupunha exatamente uma partilha do sensível em que os que agem decidindo, e os que sofrem as consequências dessas ações deveriam nos conduzir à superação desse estado de coisas. A arte, assim concebida vem a se tornar um símbolo do trabalho vivo. Mas ela apenas anteciparia o fim daqueles antagonismos que o trabalho ainda não está em condições de conquistar por e para si mesmo. No entanto, o autor alerta para a possibilidade de uma compreensão errônea a esse respeito: a de que a atual valorização do trabalho decorra exclusivamente do novo pensamento estético. Este último segue sendo uma concepção do pensamento decorrente de uma nova partilha do sensível, quaisquer que sejam as especificidades dos circuitos econômicos nos quais se inserem. Daí o seu aspecto intrinsecamente político a ser explorado por uma educação sensível atenta às novas interfaces próprias à experiência estética contemporânea.

\section{REFERÊNCIAS}

ABBAGNANO, N. Dicionário de filosofia. São Paulo: Editora Mestre Jou, 1982.

ADORNO, T. W. Minima moralia. São Paulo: Editora Ática, 1992.

ARENDT, H. Entre o passado e o futuro. São Paulo: Editora Perspectiva, 1988.

ARISTÓTELES. Poética. São Paulo: Editora Ars Poética, 1993.

BRASIL. PCN. Volume 1 e 6. Brasília: MEC/SEF, 1997.

DUARTE, N. Arte e Educação contra o fetichismo generalizado na sociabilidade contemporânea. Perspectiva, Florianópolis, SC, v. 27, n. 2, 461-479, 2009.

FABIANO, L. H. Adorno, Arte e Educação: Negócio da arte como negação. Arte e Sociedade, Campinas, SP, v. 24, n. 83, p. 495-505, 2003.

FREUD, S. Analisis terminable e interminable. In: Obras completas de Sigmund Freud. Tomo III. Madreid: Editora Biblioteca Nuova, 1981. 
LASTÓRIA, L. C. N. Ensaios de teoria crítica, ética e psicanálise: a formação do sujeito contemporâneo em questão. São Paulo: Nankin editorial, 2017.

MAFFESOLI, M. Elogio da razão sensível. Petrópolis: Editora Vozes, 1998.

PLATÃO República. Porto: Fundação Calouste Gulbenkian, 2001.

RANCIÈRE, J. A partilha do sensível. São Paulo: Editora 34, 2005.

ROSE, R. S. El misterioso caso alemán: un intento de comprender Alemania través de sus letras. Barcelona: Alba Editorial, 2007.

SCHILLER, F. A educação estética do homem. São Paulo: Editora Iluminuras, 1990.

VYGOTSKY, L. S. Psicologia da arte. São Paulo: Editora Martins Fontes, 2001.

\section{Como referenciar este artigo}

LASTÓRIA, Luiz Antonio Calmon Nabuco. Diferentes perspectivas sobre uma educação estética na atualidade. Revista on line de Política e Gestão Educacional, Araraquara, v. 24, n. 2, p. 297-313, maio/ago., 2020. e-ISSN: 1519-9029. DOI: https://doi.org/10.22633/rpge.v24i2.13163

Submetido em: 10/09/2019

Revisões requeridas: 05/10/2019

Aprovado em: 20/12/2019

Publicado em: 09/04/2020 